\title{
LC Determination of Propylene Glycol in Human Plasma After Pre-Column Derivatization with Benzoyl Chloride
}

\author{
A. Sinjewel ${ }^{1, \bowtie}$, E. L. Swart ${ }^{1}$, H. Lingeman ${ }^{2}$, A. J. Wilhelm ${ }^{1}$ \\ ${ }^{1}$ Department of Clinical Pharmacology and Pharmacy, Vrije Universiteit Medical Center, P.O. Box 7057, 1007 MB Amsterdam, \\ The Netherlands; E-Mail: sinjewel@vumc.nl \\ ${ }^{2}$ Chemistry and Pharmaceutical Sciences, Vrije Universiteit, De Boelelaan 1083, 1081 HV Amsterdam, The Netherlands
}

\begin{abstract}
A simple high-performance liquid chromatographic method, using photodiode array detection was developed for the determination of propylene glycol in human plasma and in the fluid retreived after continuous veno-venous hemofiltration. The method entailed alkaline derivatization with benzoyl chloride and ethylene glycol as internal standard. The separation of the compounds, after extraction with pentane, was carried out on a Pursuit C8 column with UVdetection at $230 \mathrm{~nm}$. Validation samples were analyzed with an accuracy between 95 and $105 \%$, and intra- and inter-day coefficients of variation of less than $8 \%$. The calibration curve was linear over a concentration range of $5-100 \mathrm{mg} \mathrm{L}^{-1}$ with a detection limit of $1 \mathrm{mg} \mathrm{L}^{-1}$. Blood plasma samples of several patients were analysed by using the prescribed method with propylene glycol concentrations varying from 5 to $98 \mathrm{mg} \mathrm{L}^{-1}$. Compared to previously described LC methods, this method is ten times more sensitive and thus suitable for use in pharmacokinetic studies of propylene glycol.
\end{abstract}

\section{Keywords}

Column liquid chromatography

Precolumn derivatization

Propylene glycol in human plasma

\section{Introduction}

Propylene glycol (1,2-propane-diol) is a chemical agent used to increase the solubilization of non-polar pharmaceuticals in aqueous solvents. It is considered safe for use as a vehicle for IV medications by the US Food and Drug Administration (FDA) [1]. Parenteral pharmaceutical preparations containing propylene glycol include lorazepam, diazepam, nitroglyc- erin, trimethoprim/sulfamethoxazole, etomidate and phenytoin. The percentage of propylene glycol in these solutions varies from 35 to $80 \%$. Although it is generally regarded as safe, potential safety concerns have been described in patients receiving these parenteral medications, especially lorazepam, which has the highest content of 80 percent of propylene glycol (PG) [2-4]. Long-term administration of high intravenous doses of lorazepam can result in propylene glycol accumulation with toxic effects. These effects include hyperosmolar metabolic acidosis, hemolysis, renal dysfunction, cardiac arrhythmias, seizures and central nervous system depression [24].

The commonly used analytical method to quantify glycols with a detection limit of several $\mathrm{mg} \mathrm{L}^{-1}$ is based on gas chromatographic separation with flame ionization (FID) or MS detection [5-7]. However during development and validation of a gas chromatographic method, we experienced absorbance of the polar propylene glycol to glass parts of the injection system. A different method, using LC - with tandem MS detection shows a limit of detection (LOD) of $0.3 \mathrm{mg} \mathrm{L}^{-1}$ in rat plasma [8]. However in the absence of expensive LC-MS-MS equipment, a different method had to be found. The lack of UV absorption and the high polarity of PG make it almost impossible to analyse it as such with LC. Derivatization with benzoyl chloride solves both problems. A quantitative method was developed by adapting a previously described LC analysis for the confirmation of ethylene glycol poisoning [9]. The FDA recommended maximal daily amount of propylene glycol is $25 \mathrm{mg} \mathrm{kg}^{-1} \mathrm{day}^{-1}$ [1], therefore a LOD in the range of several ppm is required for pharmacokinetic research purposes. In this paper, we report a relatively simple, fast and specific LC method for the determination of propylene glycol in hu- 


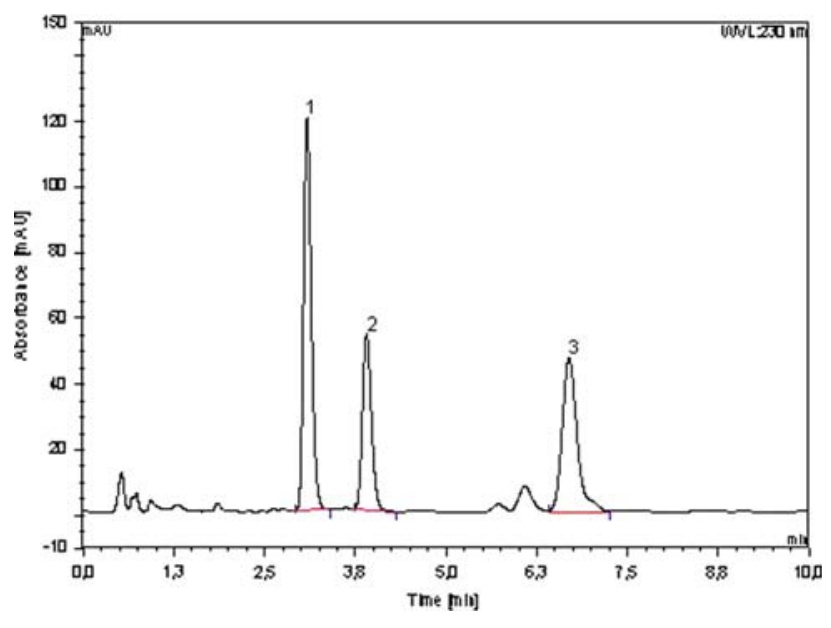

Fig. 1. Chromatogram of a plasma sample with a propylene glycol content of $20 \mathrm{mg} \mathrm{L}^{-1}$ after derivatization. Peaks $\mathbf{1}=$ internal standard, $\mathbf{2}=\mathrm{PG}$, peak $\mathbf{3}=$ unknown

man plasma by using alkaline derivatization with benzoyl chloride and UVdiode array detection.

\section{Experimental}

\section{Materials}

Propylene glycol (2 different batches, both $>99.5 \%$ pure), ethylene glycol $(>99.5 \%$ pure) and benzoyl chloride ( $>99 \%$ pure) were purchased from Sigma Aldrich (Zwijndrecht, The Netherlands). All other solvents used were of high-performance chromatography grade, purchased from VWR (West Chester, PA, USA)

\section{Instrumentation}

The HPLC system comprised an UV 6000LP photodiode array detector (Thermo-Electron, Waltham, MA, USA), a 717Plus autosampler (Waters Corporation, Milford, MA, USA), a Dionex P680 solvent delivery pump and a personal computer with Chromeleon data-acquisition and integration software (Dionex, Breda, The Netherlands). A Varian Pursuit RP-8 column $(5 \mu \mathrm{m}$, $100 \times 3 \mathrm{~mm}$ ID), fitted with a disposable RP $10 \times 2 \mathrm{~mm}$ guard column (Varian Inc, Palo Alto, CA, USA), was used for the chromatographic separation at ambient temperature. The mobile phase consisted of a mixture of $55 \% v / v$ acetonitrile and $45 \% \quad v / v$ deionized water and was refreshed daily. The analysis was run at a flow-rate of $0.75 \mathrm{~mL} \mathrm{~min}^{-1}$ with the detector operating with a spectral range from 190 to $800 \mathrm{~nm}$. Integration and quantitation was performed by using peak height ratios at the absorption maximum of $230 \mathrm{~nm}$.

\section{Stock Solutions, Calibrators and Control Samples}

A propylene glycol standard solution of $0.10 \mathrm{mg} \mathrm{mL}^{-1}$ as prepared by diluting a $1.0 \mathrm{mg} \mathrm{mL}^{-1}$ stock standard solution 10 times with deionized water. Propylene glycol calibrators were prepared in blank plasma with a concentration of $5,10,20$, 40, 60 and $100 \mathrm{mg} \mathrm{L}^{-1}$. Deionized water was added to create equal volumes of $200 \mu \mathrm{L}$. Calibrators were also used to determine intra- and inter-day accuracy and precision $(n=6)$ of the method. Validation samples were prepared by spiking blank plasma with a second batch of propylene glycol at 10, 50 and $100 \mathrm{mg} \mathrm{L}^{-1}$.

\section{Sample Preparation}

A $100 \mu \mathrm{L}$ aliquot of plasma was added to a $1.5 \mathrm{~mL}$ microcentrifuge tube (Sarstedt, Nümbrecht, Germany) and $100 \mu \mathrm{L}$ deionized water and $10 \mu \mathrm{L}$ internal standard solution of $0.3 \mathrm{mg} \mathrm{mL}^{-1}$ ethylene glycol were added. Samples and calibrators were prepared for derivatization by adding $250 \mu \mathrm{L} 4 \mathrm{M}$ sodium hydroxide and $5 \mu \mathrm{L}$ benzoyl chloride. The mixture was rotated for $10 \mathrm{~min}$ at $40 \mathrm{rpm}$ on a rotation mixer and allowed to stand for 10 min. Hereafter $400 \mu \mathrm{L}$ pentane were added and the mixture was rotated for $20 \mathrm{~min}$ on a rotation mixer at $40 \mathrm{rpm}$ and centrifuged at $10,900 \mathrm{rpm}$ for $5 \mathrm{~min}$. The supernatant was transferred into a new microcentrifuge tube (Sarstedt), evaporated to dryness under nitrogen at ambient temperature, dissolved in $150 \mu \mathrm{L}$ mobile phase, and $25 \mu \mathrm{L}$ were injected into the column. All contacts with glass parts were avoided by using polypropylene tubes and flasks.

\section{Results and Discussion}

\section{Method Development}

Earlier prescribed LC methods with UV detection have insufficient LOD's to quantify low $\mathrm{mg} \mathrm{L}^{-1} \mathrm{PG}$ levels. Sensitivity was increased by optimizing derivatization by varying time duration for mixing and extraction. Optimal values were found by derivatization for $10 \mathrm{~min}$, standing for $10 \mathrm{~min}$, and an extraction time of $20 \mathrm{~min}$.

\section{Validation}

A chromatogram obtained with plasma spiked with $20 \mathrm{mg} \mathrm{L}^{-1}$ propylene glycol and internal standard ethylene glycol after derivatization is shown in Fig. 1. Retention times for both patients and standards of propylene glycol and internal standard (ethylene glycol) after derivatization are 3.1 and 3.9 min with intra- and inter-day variations of less than 1 and $3 \%$, respectively. Spectral analysis from 190 to $800 \mathrm{~nm}$ was used to confirm peak purity and to indicate the peak identity. The intra- and inter-assay accuracy and precision are presented in Table 1. Possible outliers were tested by using Dixons Q-test. The standard calibration curve $(n=6)$, was found to be linear over the concentration range used as confirmed by analysis of variance (ANOVA) [10]. A slope of $2.222 \pm$ 0.0005 with an intercept of $1.0320 \pm$ 0.024 , and a correlation coefficient of 0.99994 was obtained. A detection limit of $1 \mathrm{mg} \mathrm{L}^{-1}$, obtained at a signal-to-noise ratio of $3: 1$, is sufficient for pharmacokinetic studies of propylene glycol in plasma. Selectivity of the method was tested for lorazepam (test concentration $2 \mathrm{mg} \mathrm{L}^{-1}$ ) and other solvents such as ethanol, benzyl alcohol and polyethylene glycol (PEG). These solvents are 
frequently used as additives in injection fluids like lorazepam. No interfering peaks were found at test concentrations of $5 \mathrm{~g} \mathrm{~L}^{-1}$. No interfering peaks we found in pooled human blank plasma.

Stability was tested for human plasma samples and spiked standards containing PG concentrations varying from 10 to $100 \mathrm{mg} \mathrm{L}^{-1}$. No significant differences were found.

The method was also tested and validated for PG analysis in CVVH fluids. CVVH fluid is an aqueous substance with electrolytes and is used in continuous veno-venous hemofiltration $(\mathrm{CVVH})$ as a replacement therapy in case of acute renal failure $[11,12]$. With reference to the analysis in human plasma, the validation of PG analysis in CVVH fluid resulted in equal or better values for the mentioned validation parameters. No interfering peaks were found in both blank CVVH fluid and human pooled CVVH fluid.

\section{Clinical Relevance}

A patient with renal failure received a continuous lorazepam infusion for $98 \mathrm{~h}$ with a cumulative dose of $39.2 \mathrm{~g}$ of propylene glycol. The concentration versus time curve of this patient is shown in Fig. 2.

\section{Conclusions}

The prescribed method is shorter, uses less chemical solvents and more important is ten times more sensitive than previously described LC methods. Several patients were analysed and blood plasma concentrations of $5-98 \mathrm{mg} \mathrm{L}^{-1}$ of propylene glycol were found. The presented LC method is sensitive, simple and suit-

Table 1. Intra- and inter-day assay accuracy and precision $(n=6)$

\begin{tabular}{|c|c|c|c|c|}
\hline \multirow[t]{2}{*}{ Concentration $\left(\mathrm{mg} \mathrm{L}^{-1}\right)$} & \multicolumn{2}{|l|}{ Intra-day } & \multicolumn{2}{|l|}{ Inter-day } \\
\hline & Accuracy $(\%)$ & $\begin{array}{l}\text { Precision } \\
(\mathrm{CV})(\%)\end{array}$ & Accuracy $(\%)$ & Precision $(\mathrm{CV})$ \\
\hline 10 & 98.9 & 5.0 & 101.0 & 4.7 \\
\hline 50 & 94.6 & 7.8 & 96.7 & 7.3 \\
\hline 99 & 104.7 & 6.9 & 104.8 & 6.9 \\
\hline
\end{tabular}

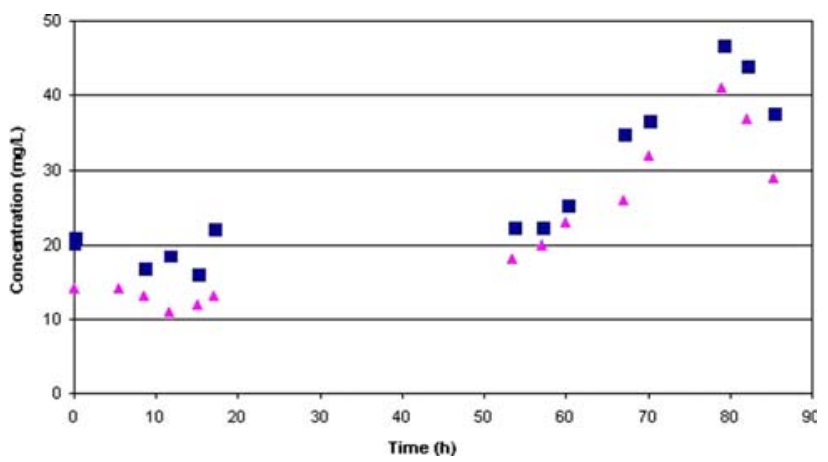

Fig. 2. Concentration versus time curve of patient with renal failure. $\mathbf{m}$ marks the concentration in plasma, $\boldsymbol{\Delta}$ the concentration in $\mathrm{CVVH}$ fluid

able to investigate propylene glycol accumulation in patients at risk and/or can be used in pharmacokinetic studies.

\section{References}

1. GRAS (1982) status of propylene glycol and propylene glycol monostearate. Food and Drug Adminstration. Final rule. Fed Regist 47 Fed. Regist

2. Arroliga AC, Shehab N, McCarthy K, Gonzales JP (2004) Crit Care Med 32(8):1709-1714

3. Chicella M, Jansen P, Parthiban A, Marlowe KF, Bencsath FA, Krueger KP, Boerth R (2002) Crit Care Med 30(12):2752-2756

4. Wilson KC, Reardon C, Theodore AC, Farber HW (2005) Chest 128(3):1674-1681
5. Houze P, Chaussard J, Harry P, Pays M (1993) J Chromatogr 619(2):251-257

6. Zhu J, Feng YL, Aikawa B (2004) J Environ Monit 6(11):881-887

7. Williams RH, Shah SM, Maggiore JA Erickson TB (2000) J Anal Toxicol 24(7):621-626

8. Gao S, Wilson DM, Edinboro LE, McGuire GM, Williams SGP, Karnes HT (2003) J Liq Chromatogr Relat Technol 26(20):3413-3431

9. Vollmer PA, Harty DC, Erickson NB, Balhon AC, Dean RA (1996) J Chromatogr B Biomed Appl 685(2):370-374

10. Shah VP, Midha KK, Findlay JW, Hill HM, Hulse JD, McGilveray IJ et al (2000) Pharm Res 17(12):1551-1557

11. Ronco C, Bellomo R, Kellum JA (2002) Adv Ren Replace Ther 9(4):229-244

12. Swart EL, de Jongh J, Zuideveld KP, Danhof M, Thijs LG, Strack van Schijndel RJ (2005) Am J Kidney Dis 45(2):360-371 